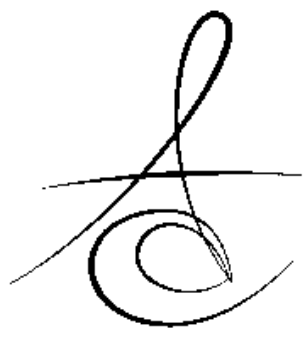

\section{AĞIZ AÇIKLIĞI KISITLI HASTADA PARÇALI ÖLÇÜ YÖNTEMİ İLE BÖLÜMLÜ ISKELET PROTEZ YAPIMI: OLGU SUNUMU}

\section{SECTIONAL IMPRESSION TECHNIQUE TO MAKE REMOVABLE PARTIAL DENTURES FOR PATIENT WITH LIMITED MOUTH OPENING: CASE REPORT *}

Dok. Ögr. Esra BİLGI ÖzYETİ** Doç. Dr. Altuğ ÇíLİNGİR**

Prof. Dr. Gülsen BAYRAKTAR*

Makale Kodu/Article code: 2978

Makale Gönderilme tarihi: 29.07.2016

Kabul Tarihi: 14.12.2016

\section{ÖZET}

Herhangi bir faktör nedeniyle ağız açıklığı kısıtlanmış hastaların protetik rehabilitasyonu ilk ölçüden protezin hastaya teslim edilmesine kadar bütün aşamalarda diş hekimi ve hasta için zorluklar içerir. Protetik diş hekimliğinde protezin yapım aşamalarında standart ölçü kaşıklarının ya da protezin ağza yerleştirilmesi ve çıkarılması zor olduğu durumlarda kullanılmak üzere bireysel ölçü kaşığı yapımında çeşitli teknikler tarif edilmiştir.

$\mathrm{Bu}$ olgu sunumunda ağız açıklığı kısıtlılığı olan ve özellikle standart ölçü kaşıkları ve yöntemleriyle ölçü alımında başarılı olunamaması nedeniyle İstanbul Üniversitesi Diş Hekimliği Fakültesi Protetik Diş Tedavisi Ana Bilim Dalına başvuran hastanın sağ, sol ve ön bölgesinden alınan alt çene ölçüsünün ağız dışında birleştirilerek model elde edilmesi ve protetik tedavisinin tamamlanması açıklanmaktadır.

Anahtar Kelimeler: Hareketli bölümlü protez, ağız açmada kısıtılık

\section{GİRİS}

Temporamandibular eklem vücuttaki en kompleks eklemlerden biridir. Temporamandibular eklemin rotasyon ve translasyon hareketleri vardır. ${ }^{1}$ Normal mandibular açılma miktarı 35-40 mm'dir. Ağız açma miktarı bu değerin altına indiğinde ağız açıklığında kısıtlılık olduğu kabul edilmektedir. ${ }^{2}$

Ağız açıklığında kısıtlıı̆̆ın sıklıkla orofasiyal kanser ameliyatları, skleroderma, travmatik yaralanma, temporamandibular eklem rahatsızlıkları, oral submukoz fibrosis ile ilişkili olduğu rapor edilmiştir. ${ }^{3}$ Herhangi

\section{ABSTRACT}

Prosthetic rehabilitation of patients with limited mouth opening due to any causative factors, presents difficulties at all stages both for the dentists and the patients, right from the preliminary impressions to the insertion of prosthesis. Several techniques have been described for use when either standard impression trays or the denture itself becomes too difficult to place and remove from the mouth.

This case explains, the prosthetic treatment of a patient consulting Department of Prosthodontics of Istanbul University, having limited mouth opening and being not successful with especially standard impression tray and techniques in making impression, so that forming a cast, combining outside of the mouth making mandibular impression at 3 stages.

Keywords: Removable partial prostheses, limited mouth opening

bir faktör nedeniyle ağız açıklığı kısıtlanmış hastaların protetik rehabilitasyonu ilk ölçüden protezin hastaya teslim edilmesine kadar bütün aşamalarda diş hekimi ve hasta için zorluklar içerir. ${ }^{4}$ Kaybedilen dişlerin ve komşu yapıların çiğneme, konuşma ve görünüm gibi ağız içi fonksiyonlarını iade ve idamesini sağlayan pek çok protez türü vardır. ${ }^{5}$ Hareketli bölümlü protezler stabilite, retansiyon ve estetiğin yanı sıra hijyenin kolay sağlanmasına olanak vermeli ve fonksiyonel kuvvetlerin doğal dişler ile alveolar kemik arasında dengelenmesini sağlamalıdır. ${ }^{6}$

\footnotetext{
* İstanbul Üniversitesi Diş Hekimliği Fakültesi Protetik Diş Tedavisi Anabilim Dal

** Trakya Üniversitesi Diş Hekimliği Fakültesi Protetik Diş Tedavisi Anabilim Dalı

\# 7. Uluslararası İstanbul Üniversitesi Diş Hekimliği Fakültesi Kongresi- Poster Sunumu, Kasım 2014
} 
Protetik diş hekimliğinde protezin yapım aşamalarında standart ölçü kaşıklarının ya da protezin ağza yerleştirilmesi ve çıkarılması zor olduğu zaman kullanılmak üzere bireysel ölçü kaşığı yapımında çeşitli teknikler tarif edilmiştir. ${ }^{7-8}$

Bu çalışmada; ağız açıklığı kısıtılıı̆ı olan ve standart ölçü kaşıkları ve yöntemleriyle ölçü alımında başarıı olunamayan ve bu nedenle İstanbul Üniversitesi Diş Hekimliği Fakültesi Protetik Diş Tedavisi Ana Bilim Dalına başvuran hastanın, iki parça halinde alınan alt çene ölçüsünün ağız dışında birleştirilerek model elde edilmesi ve protetik tedavisinin tamamlanması açıklanmaktadır.

\section{OLGU SUNUMU}

İstanbul Üniversitesi Diş Hekimliği Fakültesi Protetik Diş Tedavisi Anabilim Dalı'na alt çene posterior diş eksikliğine bağlı yemek yeme zorluğu şikayeti ile başvuran 28 yaşında omurilik felcine bağlı ortopedik engelli erkek hastada yapılan ağız dışı ve ağız içi muayenede hastada ağız açıkığının kısıtlı olduğu belirlendi. Yapılan ölçümlerde hastanın maksimum ağız açıklğı $18 \mathrm{~mm}$ olarak ölçüldü. Hastanın yapılan ağız içi muayenesinde mandibular sol 1 . ve 2 . premolar, 1 . ve 2. molar, mandibular sağ 1 . ve 2 . premolar, 1 . ve 2 . molar dişlerinin eksikliği nedeniyle alt çene Kennedy I bölümlü dişsizliğe sahip olduğu belirlendi (Resim 1).

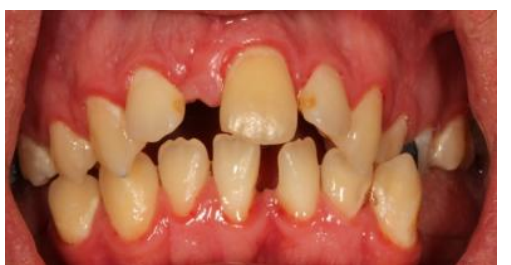

Resim 1. Hastanın tedavi öncesi ağız içi görünümü

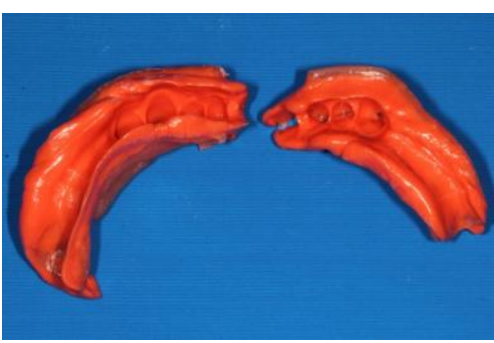

Resim 2. Bireysel ölçü kaşığı ile alınan alt çene ölçüsü

Ağız hijyeni kötü olan hastanın dişlerinde ileri derecede diş taşlarının olduğu ve yaygın çürükler oluştuğu saptandı. Ön açık kapanışın yanında üst çene posterior dişlerde antagonist diş eksikliğine bağlı ola- rak sürme ve sarkmaların oluştuğu gözlendi. Hastanın radyolojik tetkiki ve periodontal başlangıç tedavisi yapıldı. Çürük dişlerinin tedavi ve restoratif işlemleri de tamamlandıktan sonra protetik tedavi planlaması için ölçü alma aşamasına geçildi. Ancak standart metal ölçü kaşıklarının (Carl Martin, Solingen, Almanya) ağıza yerleştirilememesinden dolayı alternatif ölçü yöntemlerinin uygulanmasına karar verildi.

Hastadan metal yarım ölçü kaşıklarıyla (Carl Martin, Solingen, Almanya) alt çeneden ortada bulunan diastema bölgesinden ayrımak sureti ile sağ ve sol posterior bölgelerden ağır kıvamlı kondansasyon silikonu ölçü maddesi (Optosil Comfort, Heraeus Kulzer, Hanau, Almanya) kullanılarak ilk ölçüler alındı. Alınan ölçülerden Tip 3 sert alçı (Moldano, Heraeus Kulzer, Hanau, Almanya) ile modeller elde edildi. Dökülen yarım modellerin birleştirilmesinde kullanılacak anahtarın oluşturulması için anterior bölgeden de ağır kıvamlı kondansasyon silikonu ölçü maddesi ile bir ölçü daha alındı. Elde edilen sağ ve sol yarım çene modelleri anterior bölge ölçüsü içine yerleştirilerek elde edilen model üzerinde otopolimerizan akrilik reçine (Vertex; Vertex-Dental B.V, Zeist, Hollanda) ile bireysel ölçü kaşığı hazırlandı.

Ağız açıkığındaki kısıtılık nedeniyle akrilik bireysel kaşık elmas diskle (Meisinger, Neuss, Almanya) orta hattaki diastema aralığından iki parçaya ayrıldı. Elde edilen yarım bireysel kaşık içine orta akışkanlığa sahip kondansasyon silikonu (Xantopen Mucosa, Heraeus Kulzer, Hanau, Almanya) konulup ağıza yerleştirildi ve fonksiyonel hareketler yaptırıldı. Ölçü sertleştikten sonra ağızdan çıkarıldı (Resim 2). Anahtar yapı$\mathrm{mı}$ için yine metal yarım ölçü kaşığı ile ön bölgeden hem ağır tip, hem de akışkan tip ölçü maddesi kullanılarak iki aşamalı ölçü tekniği ile ölçü alındı (Resim 3).

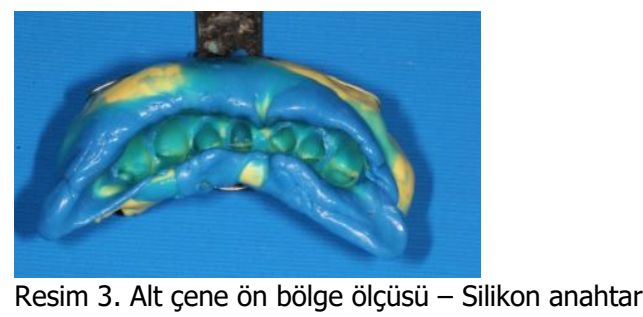

Parçalı bireysel kaşıkla hastanın sağ ve sol posterior bölgesinden alınan ölçü içine Tip 3 sert alçı (Heraeus Moldano, Almanya) döküldü. Böylece hastanın sağ ve sol posterior bölgelerinin modeli iki parça

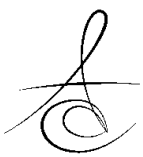


halinde elde edilmiş oldu (Resim 4). Alt sağ ve sol iki alçı modelin kenar fazlalıkları trimledikten sonra yarım modeller, metal yarım kaşıkla ön bölgeden alınan silikon anahtar içine yerleştirdi. Silikon anahtara yerleştirilen modeller etrafına kutulama işlemi yapılıp Tip 3 sert alçı ile ana model elde edildi (Resim 5).

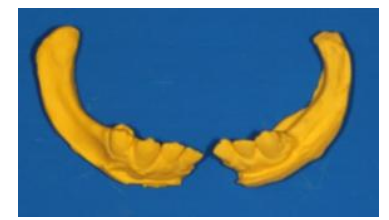

Resim 4. Alt çene sağ ve sol posterior bölge modeli

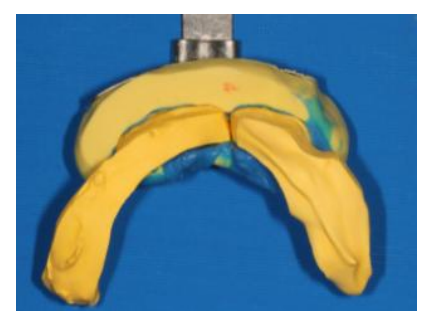

Resim 5. Silikon anahtara yerleştirilmiş alt çene sağ ve sol posterior bölge modelleri

Elde edilen ana model üzerinde ana bağlayıcı olarak lingual plak endikasyonu konuldu ve iskelet protez planlama işlemleri tamamlandı (Resim 6). İskelet protez döküm işlemi yapıldıktan sonra hasta ağzındaki kontrolleri yapıldı. Aynı seansta hastanın horizontal ve vertikal ilişkileri kaydedildi ve diş dizimi yapıldı. Daha sonra, dişli prova yapıldı ve protez geleneksel yöntemlerle bitirildi. Bir sonraki seans hasta ağzında gerekli protetik uyumlamalar yapılarak protez hastaya teslim edildi (Resim 7).

Hastanın özellikle ağız açıklığındaki kısıtlıııtan dolayı protezini kullanımı ile ilgili sorunlarının belirlenmesi için hasta 3 ay boyunca kontrol seanslarına çağırıldı. Bu seanslarda yapılan kontrol ve düzenlemelerden sonra hasta yemek yeme de dahil problem yaşamadığını ve protezini kullanabildiğini ifade etti.

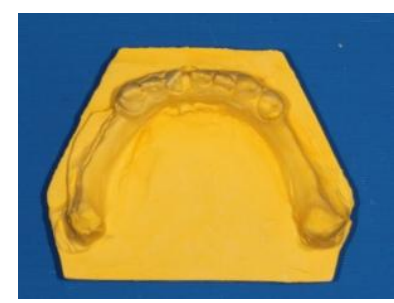

Resim 6. Ana model

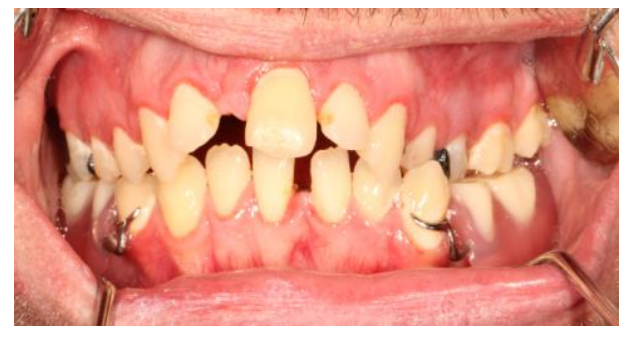

Resim 7. Hastanın tedavi sonrası ağız içi görünümü

\section{TARTIŞMA}

35-40 mm.'den daha az maksimum ağız açıklğı özellikle protetik diş tedavisi gereksinimi olan hastalarda geleneksel ölçü kaşıklarıyla ölçü alımını ve protez yapımını engellemektedir. ${ }^{2}$

Literatürlerde ağız açma kısıtlılığı olan hastalar için farklı mekanizma ve yöntemlerle oluşturulan çeşitli parçalı ölçü kaşıkları ve işlemleri tanımlanmışıı..$^{9-14}$ Luebke $^{9}$ ağız açma kısıtılıı̆ı olan hastalarda parçalı ölçü alma işlemi için otopolimerizan rezin kullanarak LEGO bloklarla birleştirilen 2 parçalı plastik ölçü kaşıklarının yapımını önermişlerdir. Mirfazaelian ${ }^{10}$ parçalı ölçü kaşı̆ının parçalarını birleştirmek için ortodontik genişletme vidası kullanımını önermektedir. Cura ve ark. ${ }^{11}$ ölçü kaşıklarının parçalarını birleştirmek için metal pin ve akrilik rezin blok kullanmışlardır. Benetti ve ark. $^{12}$ ise çalışmalarında ilk ölçü alımında, florür uygulaması için tasarlanmış fleksible plastik kaşıkları kullanmışlardır. Geckili ve ark. ${ }^{13}$ anterior ve posterior kısımlarını dikey çubukların birleştirdiği 2 parçadan oluşan bireysel kaşık kullanmışlardır. Jabbari ve ark. ${ }^{14}$ ağız açma kısıtlıı̆̆ı olan hastalarda ışıkla sertleşen kaşık materyali ve pindex sistemi kullanarak bireysel parçalı kaşık yapımını tanımlamışlardır.

Bu olgu bildiriminde ise ağız açma kısıtlılığı olan bireyde ölçü alma işlemi 3 aşamalı olarak gerçekleştirildi. Parçalı bireysel ölçü kaşığı yapımında kullanılan bu teknik özel aletler ve kompleks kilitleme mekanizmaları içermemekte ayrıca kaşık dizaynı daha basit ve ekonomik olmaktadır. Anterior bölgeden metal yarım ölçü kaşığı ile alınan ölçü parçalı bireysel ölçü kaşıkların doğru olarak birleştirilmesine olanak sağlar. Bu teknik; kaşı̆̆ın üretimi ve ikinci ölçü için ekstra iş gücü, zaman ve malzeme harcanması gibi tüm parçalı kaşık dizaynları ile ortak dezavantajlar içerir. 


\section{SONUÇ}

$\mathrm{Bu}$ olgu bildiriminde hastanın ağzına konvansiyonel kaşığın yerleştirilmesi ve çıkarılması mümkün olmadığı için hastadan metal yarım ölçü kaşıklarıyla ölçü alındı. Ön bölgeden alınan ölçü indeks olarak kullanılarak, sağ ve sol posterior bölgeden alınan ölçüler birleştirildi ve ana modeli elde edildi. Parça parça oluşturulan modellerin daha sonra birleştirilmesi sonucu elde edilen model üzerinde bitirilen protez hasta tarafından sorunsuz bir şekilde kullanılmaktadır.

Bu durum da parçalı ölçü yöntemi ile elde edilen ölçünün ve modelin hassasiyetinin hastaların protetik restorasyonunun yapımı için yeterli olduğunu göstermektedir. Klinisyenlerin de kısıtlı ağız açıklığı olan vakalarda bu ölçü yöntemini ana model oluşturmak için kullanılabilecekleri düşünülmektedir.

Esra Bilgi Özyetim, ORCID ID: https:0000-0002-3357-3740 Altuğ Çilingir, ORCID ID:0000-0002-0694-5772 Gülsen Bayraktar, ORCID ID: 0000-0002-7141-0598

\section{KAYNAKLAR}

1. Okeson PJ. Management of Temporomandibular Disorders and Occlusion 7 ed. 2013. p.4,5.

2. Sharma A, Arora P, Wazir SS. Hinged and sectional complete dentures for restricted mouth opening: A case report and review. Contemp Clin Dent 2013;4:74-7.

3. Rajendran R. Oral submucous fibrosis: etiology, pathogenesis, and future research. Bull World Health Organ 1994;72:985-96.

4. Prithviraj DR, Ramaswamy S, Romesh S. Prosthetic rehabilitation of patients with microstomia. Indian J Dent Res 2009;20:483-6.

5. Ulusoy $M$, Kevser A. Diş Hekimliğinde Hareketli Bölümlü Protezler. 2. Baskı. Ankara Üniversitesi Diş Hekimliği Fakültesi Yayınları: 2005. P.13,14,248-51,927-34.

6. Pehlivan N, Özkan P, Karacaer Ö. Klinik kron boyu kısa dişlerin protetik rehabilitasyonu: olgu sunumu. Atatürk Üniv Diş Hek Fak Derg 2012;5:29-33.

7. Dhanasomboon $\mathrm{S}$, Kiatsiriroj K. Impression procedure for a progressive sclerosis patient: a clinical report. J Prosthet Dent 2000;83:279-82.
8. McCord JF, Tyson KW, Blair IS. A sectional complete denture for a patient with microstomia. J Prosthet Dent 1989;61:645-7.

9. Luebke RJ. Sectional impression tray for patient with constricted oral opening. J Prosthet Dent 1984;52:135-7.

10. Mirfazaelian A. Use of orthodontic expansion screw in fabricating section custom trays. J Prosthet Dent 2000;83:474-5.

11. Cura C, Cotert HS, User A. Fabrication of a sectional impression tray and sectional complete denture for a patient with microstomia and trismus: a clinical report. J ProsthetDent 2003;89:540-3.

12. Benetti R, Zupi A, Toffanin A. Prosthetic rehabilitation for a patient with microstomia: a clinical report. J Prosthet Dent 2004;92:322-7.

13. Geckili $O$, Cilingir $A$, Bilgin $T$. Impression procedures and construction of a sectional denture for a patient with microstomia: a clinical report. J Prosthet Dent 2006;96:387-90.

14. Jabbari E, Savabi O, Nejatidanesh F. Use of Pindex system in fabrication of the sectional custom tray. J Prosthodont 2014;23:417-9

\section{Yazışma Adresi}

Dok. Ögr. Esra BİLGİ ÖZYETIMM

İstanbul Üniversitesi

Diş Hekimliği Fakültesi

Protetik Diş Tedavisi Anabilim Dalı esrabil88@hotmail.com 